\title{
Contrast, motion, perceptual integration, and neurocognition in schizophrenia: The role of fragile-X related mechanisms
}

\author{
Oguz Kelemen ${ }^{a}$, Tamás Kovács ${ }^{\text {b }}$, Szabolcs Kéri b,c,d,* \\ a Bács-Kiskun County Hospital, Psychiatry Center, Kecskemét, Hungary \\ b Gyula Nyírő Hospital - National Institute of Psychiatry and Addictions, Budapest, Hungary \\ c University of Szeged, Faculty of Medicine, Department of Physiology, Szeged, Hungary \\ d Budapest University of Technology and Economics, Department of Cognitive Science, Budapest, Hungary
}

\section{A R T I C L E I N F O}

\section{Article history:}

Received 26 April 2013

Received in revised form 23 June 2013

Accepted 27 June 2013

Available online 6 July 2013

\section{Keywords:}

Fragile X Syndrome

Neurocognition

Schizophrenia

Visual perception

\begin{abstract}
A B S T R A C T
Recent studies demonstrated a reduced expression of Fragile X Mental Retardation Protein (FMRP), an RNA binding protein and translation regulator, in the brain and peripheral lymphocytes of patients with schizophrenia. Low FMRP levels may be related to impaired neurodevelopmental processes and synaptic plasticity. Here, we studied the relationship between peripheral FMRP level, visual perception (contrast sensitivity, perceptual integration, motion/form perception), and neuropsychological functions in schizophrenia as measured with the Repeatable Battery for the Assessment of Neuropsychological Status (RBANS). Results revealed that patients with schizophrenia displayed lower FMRP levels in peripheral lymphocytes as compared to control individuals. We found significant correlations between FMRP levels and contrast sensitivity at low spatial and high temporal frequencies, perceptual integration, and motion perception. The relationship between FMRP level and neuropsychological functions was less pronounced than that seen in the case of visual perception, with the greatest effect for RBANS attention. FMRP level was not related to contrast sensitivity at high spatial and low temporal frequencies and form perception. This pattern of data is reminiscent to that observed in patients with Fragile $\mathrm{X}$ Syndrome (FXS). These results suggest that FMRP may be implicated in the pathogenesis of schizophrenia, possibly via the regulation of neurodevelopment, plasticity, GABA-ergic, and glutamatergic neurotransmission.
\end{abstract}

(c) 2013 Elsevier Inc. All rights reserved.

\section{Introduction}

Research during the past decades revealed a characteristic and significant perceptual and neurocognitive dysfunction in schizophrenia. Extensive evidence suggests that deficits in executive functions, attention, memory, social cognition, and visual perception markedly contribute to the psychosocial outcome of the illness (Roder \& Medalia, 2010; Sharma \& Harvey, 2000). However, the neurobiological mechanisms of neurocognitive and perceptual dysfunctions have not been clarified, and there is no satisfying treatment strategy.

Recently, we found preliminary evidence that molecular mechanisms implicated in intellectual and developmental disabilities may be related to cognition in schizophrenia, with a special reference to Fragile X Syndrome (FXS) (Kovács et al., 2013). In FXS, the Fragile X

Abbreviations: ANOVA, analysis of variance; FMRP, fragile X mental retardation protein; FXS, fragile x syndrome; GABA, gamma-aminobutyric acid; HSD, honestly significant difference; M, magnocellular; P, parvocellular; PANSS, Positive and Negative Syndrome Scale; RBANS, Repeatable Battery for the Assessment of Neuropsychological Status; SF, spatial frequency; TF, temporal frequency.

* Corresponding author at: Szabolcs Kéri, University of Szeged, Department of Physiology, Dóm sq. 10, H6720 Szeged, Hungary. Tel.: + 3620448 3530; fax: + 3662545842.

E-mail addresses: szkeri2000@yahoo.com, keri.szabolcs.gyula@med.u-szeged.hu (S. Kéri).
Mental Retardation Protein (FMRP) is absent because of an extensive nucleotide triplet expansion, leading to neurodevelopmental and cognitive anomalies. FMRP can be detected in the soma and dendritic spines of neurons serving as a translational suppressor for genes encoding proteins essential for synaptic plasticity (Bear et al., 2008; O'Donnell \& Warren, 2002; Rousseau et al., 2011). There is increasing evidence that altered expression of FMRP and its mRNA characterizes various disorders, including premature ovarian insufficiency, fragile $\mathrm{X}$-associated tremor/ataxia syndrome, autism, mood disorders, and schizophrenia (Bourgeois et al., 2009; Fatemi et al., 2010; Fatemi \& Folsom, 2011; Hagerman et al., 2010). Fatemi et al. (2010) found reduced FMRP expression in the lateral cerebellum of patients with schizophrenia and mood disorders. We confirmed these findings in peripheral lymphocytes of schizophrenia patients (Kovács et al., 2013). In addition, low FMRP expression predicted earlier illness onset and decreased IQ, which may indicate the key role of FMRP in neurodevelopment and cognition (Kovács et al., 2013).

In the present study, we aimed to extend these findings by investigating the cognitive and perceptual correlates of reduced peripheral FMRP in schizophrenia. We assessed neuropsychological functions and different aspects of visual perception. First, we examined immediate and delayed memory, attention, language, and visuospatial functions using the Repeatable Battery for the Assessment of Neuropsychological 
Status (RBANS) (Randolph et al., 1998). Second, we assessed multiple levels of visual perception as delineated in the Cognitive Neuroscience Treatment Research to Improve Cognition in Schizophrenia (CNTRICS) project (Butler et al., 2008, 2012). Specifically, we studied visual contrast sensitivity, perceptual integration, and motion/form perception. Our previous results indicated that in healthy volunteers contrast sensitivity for low spatial and high temporal frequency gratings (rough resolution and dynamic changes of stimuli) and motion perception were associated with FMRP expression, whereas contrast sensitivity for high spatial frequency/static gratings (fine resolution of stimuli) and form perception were not (Kéri \& Benedek, 2011, 2012) (Fig. 1). This is consistent with the eminent role of FMRP in the development of the magnocellular retino-geniculo-striatal visual pathways (Kogan et al., 2004; Zangenehpour et al., 2009). Therefore, we hypothesized that reduced FMRP expression would be associated with an impaired processing of low spatial/high temporal frequency gratings and coherently moving patterns in patients with schizophrenia. We also investigated, for the first time, the possible relationship between FMRP expression and perceptual integration.

\section{Materials and methods}

\subsection{Participants}

We enrolled 50 patients with schizophrenia and 50 healthy controls with a negative family history for psychotic disorders at the National Institute of Psychiatry and Addictology, Budapest and Bács-Kiskun County Hospital, Kecskemét, Hungary. None of the patients was included in the Kovács et al.'s (2013) study. The diagnosis was based on structured clinical interviews (First et al., 1996). We had access to the complete medical record of the patients. Patients with schizophrenia received antipsychotic medications at the time of testing (risperidone, olanzapine, quetiapine, haloperidol, aripiprazole, zuclopenthixol, amisulpride). We converted the daily dose of antipsychotics to chlorpromazineequivalent units (Woods, 2003). All patients received the Positive and Negative Syndrome Scale (PANSS) (Kay et al., 1987). All participants had normal or corrected-to-normal visual acuity. The clinical and demographic data are depicted in Table 1. The study was done in accordance with the Declaration of Helsinki. We obtained written informed consent

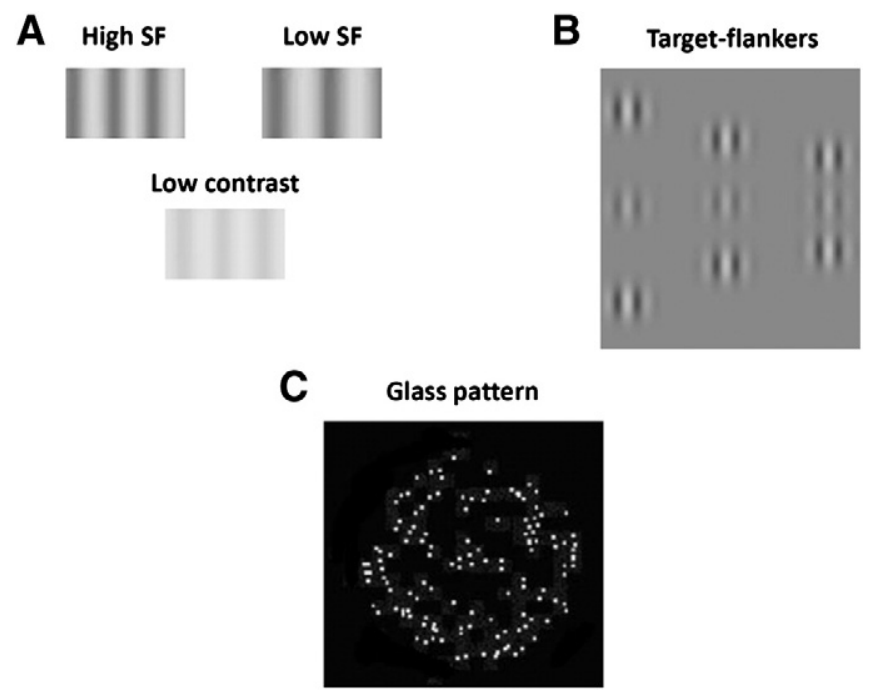

Fig. 1. Stimuli used in psychophysical tests of visual perception. A. Sinusoida luminance-contrast gratings with different spatial frequencies and contrasts. Gratings were modulated using counterphase flickering (temporal frequency, Hz). B. Gabor patches with different target-flanker distances (target: low-contrast central patch; flankers: high-contrast lateral patches). C. Glass patterns used for form and motion coherence measurements.
Table 1

Demographic and clinical characteristics of the participants.

\begin{tabular}{lll}
\hline & $\begin{array}{l}\text { Schizophrenia } \\
(\mathrm{n}=50)\end{array}$ & $\begin{array}{l}\text { Control } \\
(\mathrm{n}=50)\end{array}$ \\
\hline Male/female & $31 / 19$ & $31 / 19$ \\
Age (years) & $42.7(9.2)$ & $44.1(9.0)$ \\
Age of illness onset (years) & $23.6(6.6)$ & - \\
PANSS positive & $21.2(6.4)$ & - \\
PANSS negative & $19.8(7.5)$ & - \\
PANSS general & $49.7(10.0)$ & - \\
Antipsychotics (chlorpromazine-equivalent, mg/day) & $455.0(185.4)$ & - \\
\hline
\end{tabular}

Data are mean (standard deviation). PANSS - Positive and Negative Syndrome Scale.

from each participant. The study was approved by the institutional ethics committee.

\subsection{Neuropsychological assessment}

We used the RBANS comprising 12 tests classified according to five index scores (Gold et al., 1999; Juhász et al., 2003; Randolph et al., 1998). Each index score is standardized (normal mean: $100, S D=15$ based on a normative study group of 200 healthy Hungarian volunteers, 20-80 years of age). The RBANS index domains and tests are as follows: (1) immediate memory (word list learning [ 10 words repeated in four trials], story recall in two trials); (2) language (confrontation naming of 10 pictures, category fluency); (3) visuospatial functions (figure copy, line orientation); (4) attention (digit span, digit-symbol coding); and (5) delayed memory (delayed recall of the story, complex figure, and word list, recognition of the word list). The RBANS has two psychometrically matched forms. In this study, we used version " $A$ ".

\subsection{Visual perception}

\subsubsection{Stimulus presentation and response collection}

We used a VP2765-LED-27" monitor (ViewSonic, Walnut, CA; refresh rate: $60 \mathrm{~Hz}$, resolution: $1920 \times 1080$ pixel; viewing distance: $50 \mathrm{~cm}$; output luminance: $65 \mathrm{~cd} / \mathrm{m}^{2}$; background luminance: $5 \mathrm{~cd} / \mathrm{m}^{2}$ ) controlled by a Dell XPS workstation. All experimental procedures have been extensively described in previous publications, and here only brief descriptions are provided with references to methodological details.

\subsubsection{Contrast sensitivity}

We undertook these measurements to evaluate early-stage, low-level visual information processing, including pathways stemming from the retina and projecting to the lateral geniculate nucleus and then to the primary visual cortex. We used two types of sinusoidal luminance-contrast gratings: stimuli with low spatial frequency (SF) and high temporal frequency (TF) $(0.3$ cycle/degree and $18 \mathrm{~Hz}$, respectively) and stimuli with high SF and low TF (10 cycles/degree and $1 \mathrm{~Hz}$, respectively) (Fig. 1a). Participants gave oral responses indicating whether they saw the grating or not, and the experimenter entered the responses on the keyboard. If the participant was not able to detect the grating, the contrast was increased and vice versa (reversals) using a staircase procedure. The contrast threshold was the average of the last 12 reversals. Contrast sensitivity was the inverse of contrast threshold (Halász et al., 2013; Kéri \& Benedek, 2009; Kogan et al., 2004).

\subsubsection{Perceptual integration}

This procedure tests how early visual areas are able to bind and assemble basic perceptual details to create contours (Kéri et al., 2005a,b; Must et al., 2004; Polat \& Sagi, 1993). Stimuli were Gabor patches (SF: 6.7 cycles/degree). There was a central Gabor patch (target) and two high-contrast flankers (Fig. 1b). The distance between target and flankers was 1 or $3 \lambda$ ( $\lambda$ : reciprocal of SF). Trials without flankers were also presented. We measured contrast threshold for the target Gabor patch using a staircase procedure and determined threshold 
changes at each target-to-flanker distance relative to targets presented without flankers (Kéri et al., 2005a,b; Must et al., 2004; Polat \& Sagi, 1993).

\subsubsection{Motion and form perception}

We used Glass pattern stimuli to determine motion and form coherence threshold (Glass, 1969; Kéri \& Benedek, 2012; McKendrick et al., 2006) (Fig. 1c). During the measurement of form coherence threshold, coherent dots were replaced with randomly positioned noise dots (e.g., 50\% coherence means that half of the dots were positioned concentrically, whereas the other half of the dots was placed randomly). During the measurement of motion coherence threshold, a fraction of randomly chosen dots moved in the same signal direction, while all other dots moved in random ( $9 \mathrm{~min}$ arc/frame, $3^{\circ} / \mathrm{s}$ ). We measured coherence thresholds (\% of concentrically positioned and coherently moving dots necessary for stimulus detection) using a staircase procedure (Kéri \& Benedek, 2012; McKendrick et al., 2006).

\subsection{Measurement of FMRP}

For the quantitative evaluation of FMRP level from peripheral blood lymphocytes, we followed the protocol of Iwahashi et al. (2009), an enzyme-linked immunosorbent assay (ELISA) method, which provides an accurate and standardized measurement of FMRP.

\subsection{Statistical analysis}

We used STATISTICA 11 (StatSoft, Inc., Tulsa) and Prism 6 (GraphPad, Inc., La Jolla) for data analysis. After the analysis of data distribution with Kolmogorov-Smirnov tests, we used analyses of variance (ANOVAs) followed by Tukey Honestly Significant Difference (HSD) tests. Where appropriate, measures were compared with two-tailed $t$ test. We calculated Cohen's effect size values $(d)$. To investigate the relationship between FMRP and neuropsychological and perceptual measures, we calculated Pearson's product moment correlation coefficients and used mediansplit analyses. Multiple comparisons were corrected according to the Bonferroni method. The level of statistical significance was $\alpha<0.05$.

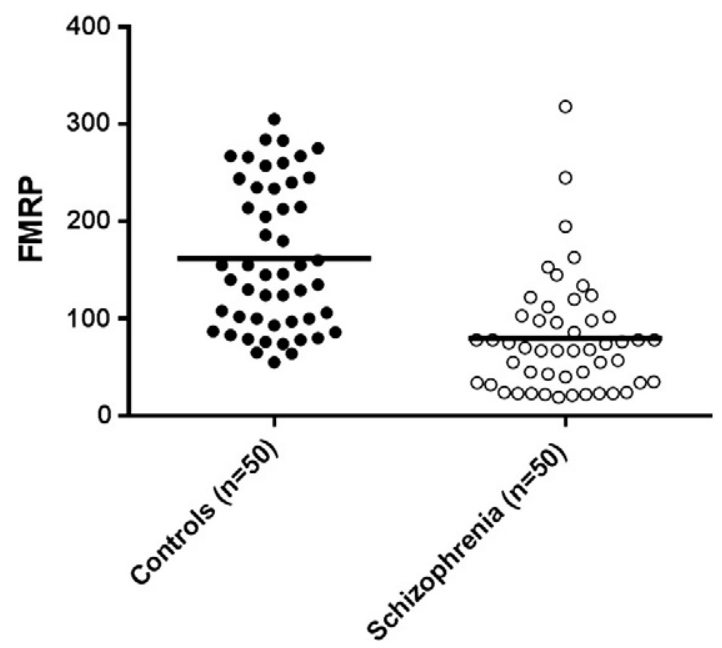

Fig. 2. Fragile X Mental Retardation Protein (FMRP) levels in patients with schizophrenia and healthy control volunteers. FMRP levels were calculated relative to a reference standard lymphocyte extract (Iwahashi et al., 2009). The dots show individual values, whereas the horizontal lines indicate mean in each group (for statistical details, see Results Section 3.1).

\section{Results}

\subsection{Peripheral FMRP level}

Patients with schizophrenia displayed a significantly reduced level of FMRP relative to controls (schizophrenia: $79.8(S D=59.7)$; controls: $162.1(S D=74.6) ; t(98)=6.10, p<0.001)$ (Fig. 2 ).

\subsection{Neuropsychological performance}

The results are depicted in Table 2. There was a generalized neuropsychological deficit in schizophrenia, which was the most pronounced in the case delayed memory. Language was relatively less affected.

\subsection{Contrast sensitivity}

The ANOVA indicated significant main effects of group (schizophrenia vs. controls) $\left(F(1,98)=93.9 ; p<0.001 ; \eta^{2}=0.49\right)$ and stimulus type (low SF/high TF vs. high SF/low TF) $\left(F(1,98)=126.14, p<0.001 ; \eta^{2}=\right.$ $0.56)$. There was a two-way interaction between group and stimulus type $\left(F(1,98)=5.78, \quad p<0.05 ; \eta^{2}=0.06\right)$. Patients with schizophrenia showed reduced contrast sensitivity for both stimulus types as compared with control individuals (Tukey HSD, $p<0.001$ ). The two-way interaction appeared because the impairment was more severe in the case of stimuli with low SF/high TF relative to high SF/low TF (Table 3).

\subsection{Perceptual integration}

The ANOVA revealed significant main effects of group (schizophrenia vs. controls) $\left(F(1,98)=5.61 ; p<0.05 ; \eta^{2}=0.05\right)$ and stimulus type ( $1 \lambda$ vs. $3 \lambda$ target-flanker distance) $\left(F(1,98)=554.87, p<0.001 ; \eta^{2}=\right.$ $0.85)$. There was a significant two-way interaction between group and stimulus type $\left(F(1,98)=12.34, p<0.01 ; \eta^{2}=0.11\right)$. The post-hoc analysis revealed less negative values at $3 \lambda$ target-flanker distance in patients with schizophrenia relative to controls $(p<0.001)$. Patients and control showed similar values at $1 \lambda$ target-flanker distance $(p>0.5)$ (Table 3$)$.

\subsection{Motion and form perception}

There was a significant main effect of group $(F(1,98)=46.81$; $p<0.001 ; \eta^{2}=0.32$ ). The main effect of stimulus type (motion vs. form coherence) was not significant $(p>0.5)$. We found a significant two-way interaction between group and stimulus type $(F(1,98)=6.93$; $\left.p<0.05 ; \eta^{2}=0.07\right)$. Patients with schizophrenia had higher coherence thresholds than control individuals for form $(p<0.05)$ and motion $(p<0.001)$. As shown in Table 3, elevated threshold in schizophrenia patients, relative to control volunteers, was greater for motion than for form.

Table 2

RBANS results.

\begin{tabular}{lllllll}
\hline & $\begin{array}{l}\text { Schizophrenia } \\
(\mathrm{n}=50)\end{array}$ & $\begin{array}{l}\text { Controls } \\
(\mathrm{n}=50)\end{array}$ & $d f$ & $t$ & $p$ & $d$ \\
\hline Attention & $80.9(17.1)$ & $96.3(15.3)$ & 98 & 4.73 & $<0.001$ & 0.86 \\
Immediate memory & $80.3(15.6)$ & $98.7(14.3)$ & 98 & 6.16 & $<0.001$ & 1.05 \\
Delayed memory & $77.7(13.8)$ & $99.1(13.9)$ & 98 & 7.73 & $<0.001$ & 1.22 \\
Visuospatial functions & $82.6(15.9)$ & $95.9(14.4)$ & 98 & 4.36 & $<0.001$ & 0.81 \\
Language & $89.2(17.4)$ & $98.1(18.2)$ & 98 & 2.50 & 0.01 & 0.49 \\
\hline
\end{tabular}

Data are mean (standard deviation). Groups were compared with two-tailed $t$ tests. Cohen's $d$ values (effect size) are also shown. RBANS: Repeatable Battery for the Assessment of Neuropsychological Status. 
Table 3

Results from the visual perceptual tests.

\begin{tabular}{|c|c|c|c|}
\hline & $\begin{array}{l}\text { Schizophrenia } \\
(\mathrm{n}=50)\end{array}$ & $\begin{array}{l}\text { Controls } \\
(n=50)\end{array}$ & $d$ \\
\hline Low SF/high TF contrast sensitivity & $68.2(10.0)$ & $88.2(9.9)$ & 1.43 \\
\hline High SF/low TF contrast sensitivity & $53.2(11.8)$ & $65.1(15.0)$ & 0.81 \\
\hline Form coherence (\%) & $32.9(11.4)$ & $26.6(10.1)$ & 0.56 \\
\hline Motion coherence $(\%)$ & $38.7(14.8)$ & $23.4(9.7)$ & 1.05 \\
\hline Contrast threshold change at $1 \lambda$ (log-unit) & $0.23(0.1)$ & $0.25(0.1)$ & 0.18 \\
\hline Contrast threshold change at $3 \lambda$ (log-unit) & $-0.08(0.1)$ & $-0.18(0.1)$ & 0.83 \\
\hline
\end{tabular}

Data are mean (standard deviation). SF: spatial frequency; TF: temporal frequency; Cohen's $d$ values (effect size) are shown.

\subsection{Correlations between neuropsychological and visual performance and FMRP levels}

Table 4 shows the correlation coefficients. Patients and control individuals displayed a similar pattern of correlations, although these relationships were more robust in patients than in control individuals. FMRP levels were associated with better contrast sensitivity at low SF/ high TF, RBANS attention, motion perception, and perceptual integration.

\subsection{Median split analysis of RBANS and visual perceptual performance}

We divided control participants and patients with schizophrenia into two groups using the median of the FMRP level (individuals with low and high FMRP level). In control individuals, there were significant differences between high and low FMRP groups in contrast sensitivity at low $\mathrm{SF} /$ high $\mathrm{TF}$ (high: $92.8(S D=8.8)$; low: $83.6(S D=8.5)$; $t(48)=-3.76, p<0.005$ ) and in motion coherence (high: 20.2 $(S D=5.5)$; low: $26.5(S D=11.8) ; t(48)=2.41, p<0.05)$.

In patients with schizophrenia, we found significant differences between high and low FMRP groups in contrast sensitivity at low SF/high TF (high: $73.0(S D=8.9)$; low: $63.4(S D=8.3) ; t(48)=-3.92$, $p<0.001$ ), motion perception (high: $30.2(S D=10.2)$; low: 47.2 $(S D=13.9) ; t(48)=4.92, p<0.001)$, contrast threshold change at $3 \lambda$ target-flanker distance (high: $-0.14(S D=0.1)$; low: -0.03 $(S D=0.09) ; t(48)=4.16, p<0.001)$, and RBANS attention (high: $87.5(S D=15.6)$; low: $74.4(S D=14.1) ; t(48)=-2.92, p<0.05)$.

\subsection{Correlation with antipsychotic doses}

We did not find a significant correlation between chlorpromazineequivalent antipsychotic dose and FMRP levels. The antipsychotic dose did not correlate with the test performances $(-0.2<r \mathrm{~s}<0.2$, ps $>0.1)$.

\section{Discussion}

The findings of the present study suggest that reduced FMRP plays a key role in the visual dysfunction associated with schizophrenia. FMRP may also modulate visual perception in healthy individuals (Kéri \& Benedek, 2011, 2012). We observed trend-level and consistent positive relationships between FMRP levels and neuropsychological functions, but even when it reached statistical significance (attention and immediate memory), it hardly passed the criteria of correction for multiple comparisons. Therefore, it seems that FMRP has a greater impact on particular domains of visual perception assessed by psychophysical tasks than on neuropsychological functions assessed by standard pen-and-paper tests.

The relationship between FMRP and perception was selective for certain visual functions, similarly to our previous data from healthy individuals (Kéri \& Benedek, 2011, 2012). Specifically, we observed a correlation between FMRP level and contrast sensitivity for low SF/high TF gratings, motion perception, and perceptual integration. There was no such relationship between FMRP and contrast sensitivity at high SF/ low TF and form perception. These findings can be interpreted in the framework of the magnocellular $(\mathrm{M})$ /parvocellular $(\mathrm{P})$ precortical visual pathways and their cortical recipients (dorsal occipito-parietal and ventral occipito-temporal streams, respectively). Low SF/high TF gratings are thought to preferably stimulate $M$ pathways, whereas high $\mathrm{SF} /$ low TF gratings activate $\mathrm{P}$ pathways. M pathways provide essential information to dorsal stream areas responsible for motion perception and visuospatial coordination, whereas $\mathrm{P}$ pathways project to ventral stream areas participating in form and color perception (for an overview, see Gilbert, 2013; Nassi \& Callaway, 2009). In schizophrenia, there is an impairment of both systems, but $\mathrm{M}$ pathways seem to be dominantly affected (Butler et al., 2008). The fact that FMRP might be implicated in the appropriate organization and functioning of $\mathrm{M}$ pathways, but not $\mathrm{P}$ pathways, is in well accordance with this model (Kogan et al., 2004; Zangenehpour et al., 2009).

However, this model has limitations. First, the selective stimulation and functional unity of $\mathrm{M}$ and $\mathrm{P}$ pathways have been debated (Goodbourn et al., 2012; Skottun \& Skoyles, 2007). Second, M and P pathways interact in the primary visual cortex (Sawatari \& Callaway, 1996), and therefore their strictly separate contribution to dorsal and ventral systems is dubious. Third, recent evidence suggests a "patchwork" organization of higher-level visual cortical areas instead of functionally separated dorsal and ventral streams (de Haan \& Cowey, 2011). Nevertheless, there is substantial evidence from several studies that stimulus characteristics (e.g., spatial frequency, contrast, motion, and color) significantly and differentially affect behavioral performance and brain activation in schizophrenia (e.g., Butler et al., 2007; Calderone et al., 2013; Chen, 2011; Graham \& Meng, 2011; Kéri et al., 2004, 2012; Martínez et al., 2008; McBain et al., 2010; O'Donnell et al., 1996, 2002; Schechter et al., 2005). Beyond generalized deficits in contrast sensitivity and coherence threshold, the present study demonstrated more severe impairments in patients for low SF and moving stimuli than for high SF and form stimuli, which is consistent with the above-discussed findings. Moreover, the differential effect of FMRP lends further support for the existence of separate systems for the processing of low SF/motion and high $\mathrm{SF} /$ form.

We also found a relationship between FMRP level and perceptual integration, which may be mediated by lateral connections between processing units in early visual cortical areas (Kovács, 1996; Polat \& Sagi, 1993; for a review of perceptual integration and organization in schizophrenia, see Silverstein \& Keane, 2011). At specific distances, these lateral interactions are inhibitory (e.g., $1 \lambda$ target-flanker distance), whereas in other

Table 4

Correlations between FMRP level and neuropsychological and visual perceptual measures.

\begin{tabular}{|c|c|c|c|c|c|c|c|c|c|c|c|}
\hline & CS1 & $\mathrm{CS} 2$ & Att & MemI & MemD & VSP & Lang & Form & Motion & $1 \lambda$ & $3 \lambda$ \\
\hline $\begin{array}{l}\text { Controls } \\
\qquad(\mathrm{n}=50)\end{array}$ & $0.69^{* *}$ & -0.20 & $0.32^{*}$ & 0.26 & 0.11 & 0.09 & 0.15 & 0.13 & $-0.41^{*}$ & -0.05 & $-0.31^{*}$ \\
\hline $\begin{array}{l}\text { Schizophrenia } \\
\quad(\mathrm{n}=50)\end{array}$ & $0.67^{* *}$ & $-0.28^{*}$ & $0.54^{* *}$ & $0.30^{*}$ & 0.19 & 0.22 & 0.28 & 0.0 & $-0.57^{* *}$ & 0.18 & $-0.61^{* *}$ \\
\hline
\end{tabular}

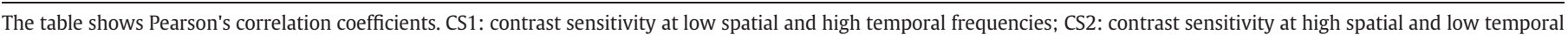

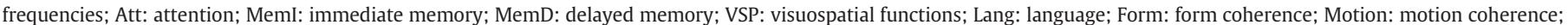
$1 \lambda$ : contrast threshold change at $1 \lambda$ target-flanker distance; $3 \lambda$ : contrast threshold change at $3 \lambda$ target-flanker distance.

$* \mathrm{p}<0.05$.

** $\mathrm{p}<0.002$ (Bonferroni-corrected threshold). 
distances it is excitatory (e.g., $3 \lambda$ target-flanker distance). In the latter case, flankers enhance contrast detection at the target patch, and therefore contrast threshold is reduced relative to the scenario when the target stimulus is presented without flankers (Polat \& Sagi, 1993). This excitatory effect is diminished in schizophrenia (Kéri et al., 2005a,b; Must et al., 2004). Data from the present study raise the possibility that FMRP may have an effect on the development and functional integrity of lateral connections in early visual cortical areas. This hypothesis must be confirmed by animal studies.

Our results must be interpreted with caution. Development and functional plasticity of neuronal circuits, such as domains of the visual system, are not regulated by a single molecular factor, and therefore FMRP cannot be considered as a sole master regulator. Nevertheless, the high expression of FMRP in M cells, but not in P cells, and the marked loss of certain visual function in FXS and premutation carriers strongly indicate its key role (Kéri \& Benedek, 2009; Kogan et al., 2004). Although evidence suggests that in FXS FMRP is abnormally expressed in both brain tissue and peripheral lymphocytes (e.g., Devys et al., 1993; Kogan et al., 2004; Pieretti et al., 1991; Willemsen et al., 1997), the exact relationship between neuronal and peripheral changes in neuropsychiatric disorders must be directly verified.

FMRP is an RNA binding protein regulating the translation of hundreds of transcripts in the brain, with a special reference to subunits of gamma-amino butyric acid (GABA) and metabotropic glutamate receptors (Heulens \& Kooy, 2011). Altered FMRP levels are not specific for schizophrenia: similar findings have been revealed in bipolar disorder, major depressive disorder, and autism without FXS (Fatemi \& Folsom, 2011; Fatemi et al., 2010, 2011, 2013). The visual phenotype of mood disorders and autism is partly similar to that of schizophrenia (e.g., Dakin \& Frith, 2005; Kéri et al., 2007; Laycock et al., 2007), but more data are indispensable to obtain conclusive evidence and to explore the shared role of FMRP. Overall, FMRP may be a missing link in the GABA and glutamate hypothesis of schizophrenia and other neuropsychiatric disorders and may provide new targets for pharmacological agents crossing the boundary of classic diagnostic categories.

\section{Acknowledgments}

This study was supported by the Hungarian Research Fund (TÁMOP-4.2.2.A-11/1/KONV-2012-0052).

\section{References}

Bear MF, Dölen G, Osterweil E, Nagaraja N. Fragile X: translation in action. Neuropsychopharmacology 2008;33:84-7.

Bourgeois JA, Coffey SM, Rivera SM, Hessl D, Gane LW, Tassone F, et al. A review of fragile X premutation disorders: expanding the psychiatric perspective. J Clin Psychiatry 2009;70:852-62.

Butler PD, Martinez A, Foxe JJ, Kim D, Zemon V, Silipo G, et al. Subcortical visual dysfunction in schizophrenia drives secondary cortical impairments. Brain 2007;130:417-30.

Butler PD, Silverstein SM, Dakin SC. Visual perception and its impairment in schizophrenia. Biol Psychiatry 2008;64:40-7.

Butler PD, Chen Y, Ford JM, Geyer MA, Silverstein SM, Green MF. Perceptual measurement in schizophrenia: promising electrophysiology and neuroimaging paradigms from CNTRICS. Schizophr Bull 2012;38:81-91.

Calderone DJ, Martinez A, Zemon V, Hoptman MJ, Hu G, Watkins JE, et al. Comparison of psychophysical, electrophysiological, and fMRI assessment of visual contrast responses in patients with schizophrenia. Neuroimage 2013;67:153-62.

Chen Y. Abnormal visual motion processing in schizophrenia: a review of research progress. Schizophr Bull 2011;37:709-15.

Dakin S, Frith U. Vagaries of visual perception in autism. Neuron 2005;48:497-507.

de Haan EH, Cowey A. On the usefulness of 'what' and 'where' pathways in vision. Trends Cogn Sci 2011;15:460-6.

Devys D, Lutz Y, Rouyer N, Bellocq JP, Mandel JL. The FMR-1 protein is cytoplasmic, most abundant in neurons and appears normal in carriers of a fragile $\mathrm{X}$ premutation. Nat Genet 1993;4:335-40.

Fatemi SH, Folsom TD. The role of fragile X mental retardation protein in major mental disorders. Neuropharmacology 2011;60:1221-6.

Fatemi SH, Kneeland RE, Liesch SB, Folsom TD. Fragile X mental retardation protein levels are decreased in major psychiatric disorders. Schizophr Res 2010;124: 246-7.
Fatemi SH, Folsom TD, Kneeland RE, Liesch SB. Metabotropic glutamate receptor 5 upregulation in children with autism is associated with underexpression of both fragile X mental retardation protein and GABAA receptor beta 3 in adults with autism. Anat Rec (Hoboken) 2011;294:1635-45.

Fatemi SH, Folsom TD, Rooney RJ, Thuras PD. mRNA and protein expression for novel GABAA receptors $\theta$ and $\rho 2$ are altered in schizophrenia and mood disorders; relevance to FMRP-mGluR5 signaling pathway. Transl Psychiatry 2013;3:e271.

First MB, Spitzer RL, Gibbon M, Williams JBW. Structured Clinical Interview for DSM-IV Axis I Disorders, Clinician Version (SCID-CV). Washington, DC: American Psychiatric Press; 1996.

Gilbert CD. The constructive nature of visual perception. In: Kandel ER, Schwartz JH, Jessel TM, Siegelbaum SA, Hudspeth AJ, editors. Principles of neural sciences. New York: McGraw Hill; 2013. p. 556-76.

Glass L. The Moire effect from random dots. Nature 1969;223:578-80.

Gold JM, Queern C, Iannone VN, Buchanan RW. Repeatable battery for the assessment of neuropsychological status as a screening test in schizophrenia I: sensitivity, reliability, and validity. Am J Psychiatry 1999;156:1944-50.

Goodbourn PT, Bosten JM, Hogg RE, Bargary G, Lawrance-Owen AJ, Mollon JD. Do different 'magnocellular tasks' probe the same neural substrate? Proc Biol Sci 2012;279:4263-71.

Graham D, Meng M. Altered spatial frequency content in paintings by artists with schizophrenia. i-Perception 2011;2:1-9.

Hagerman R, Hoem G, Hagerman P. Fragile X and autism: intertwined at the molecular level leading to targeted treatments. Mol Autism 2010;1:12.

Halász I, Levy-Gigi E, Kelemen O, Benedek G, Kéri S. Neuropsychological functions and visual contrast sensitivity in schizophrenia: the potential impact of comorbid posttraumatic stress disorder (PTSD). Front Psychol 2013:4:136.

Heulens I, Kooy F. Fragile X syndrome: from gene discovery to therapy. Front Biosci 2011;16:1211-32.

Iwahashi C, Tassone F, Hagerman RJ, Yasui D, Parrott G, Nguyen D, et al. A quantitative ELISA assay for the fragile $\mathrm{x}$ mental retardation 1 protein. J Mol Diagn 2009;11:281-9.

Juhász LZ, Kemény K, Linka E, Sántha J, Bartkó G. The use of RBANS test (Repeatable Battery for the Assessment of Neuropsychological Status) in neurocognitive testing of patients suffering from schizophrenia and dementia. Ideggyogy Sz 2003;56:303-8.

Kay SR, Fiszbein A, Opler LA. The positive and negative syndrome scale (PANSS) for schizophrenia. Schizophr Bull 1987;13:261-76.

Kéri S, Benedek G. Visual pathway deficit in female fragile X premutation carriers: a potential endophenotype. Brain Cogn 2009;69:291-5.

Kéri S, Benedek G. Fragile X protein expression is linked to visual functions in healthy male volunteers. Neuroscience 2011;192:345-50.

Kéri S, Benedek G. Why is vision impaired in fragile X premutation carriers? The role of fragile X mental retardation protein and potential FMR1 mRNA toxicity. Neuroscience 2012;206:183-9.

Kéri S, Kelemen O, Benedek G, Janka Z. Vernier threshold in patients with schizophrenia and in their unaffected siblings. Neuropsychology 2004;18:537-42.

Kéri S, Kiss I, Kelemen O, Benedek G, Janka Z. Anomalous visual experiences, negative symptoms, perceptual organization and the magnocellular pathway in schizophrenia: a shared construct? Psychol Med 2005a;35:1445-55.

Kéri S, Kelemen O, Benedek G, Janka Z. Lateral interactions in the visual cortex of patients with schizophrenia and bipolar disorder. Psychol Med 2005b;35:1043-51.

Kéri S, Benedek G, Janka Z. Vernier threshold and the parallel visual pathways in bipolar disorder: a follow-up study. Prog Neuropsychopharmacol Biol Psychiatry 2007;31:86-91.

Kéri S, Szamosi A, Benedek G, Kelemen O. How does the hippocampal formation mediate memory for stimuli processed by the magnocellular and parvocellular visua pathways? Evidence from the comparison of schizophrenia and amnestic mild cognitive impairment (aMCI). Neuropsychologia 2012;50:3193-9.

Kogan CS, Boutet I, Cornish K, Zangenehpour S, Mullen KT, Holden JJ, et al. Differential impact of the FMR1 gene on visual processing in fragile X syndrome. Brain 2004;127: 591-601.

Kovács I. Gestalten of today: early processing of visual contours and surfaces. Behav Brain Res 1996;82:1-11.

Kovács T, Kelemen O, Kéri S. Decreased fragile X mental retardation protein (FMRP) is associated with lower IQ and earlier illness onset in patients with schizophrenia. Psychiatry Res 2013. http://dx.doi.org/10.1016/j.psychres.2012.12.022. [2013 Jan 17. doi:pii: S0165-1781(12)00845-1].

Laycock R, Crewther SG, Crewther DP. A role for the 'magnocellular advantage' in visual impairments in neurodevelopmental and psychiatric disorders. Neurosci Biobehav Rev 2007;31:363-76.

Martínez A, Hillyard SA, Dias EC, Hagler Jr DJ, Butler PD, Guilfoyle DN, et al. Magnocellular pathway impairment in schizophrenia: evidence from functional magnetic resonance imaging. J Neurosci 2008;28:7492-500.

McBain R, Norton D, Chen Y. Differential roles of low and high spatial frequency content in abnormal facial emotion perception in schizophrenia. Schizophr Res 2010;122:151-5.

McKendrick AM, Badcock DR, Gurgone M. Vernier acuity is normal in migraine, whereas global form and global motion perception are not. Invest Ophthalmol Vis Sci 2006;47:3213-9.

Must A, Janka Z, Benedek G, Kéri S. Reduced facilitation effect of collinear flankers on contrast detection reveals impaired lateral connectivity in the visual cortex of schizophrenia patients. Neurosci Lett 2004;357:131-4.

Nassi JJ, Callaway EM. Parallel processing strategies of the primate visual system. Nat Rev Neurosci 2009;10:360-72.

O'Donnell WT, Warren ST. A decade of molecular studies of fragile X syndrome. Ann Rev Neurosci 2002;25:315-38.

O'Donnell BF, Swearer JM, Smith LT, Nestor PG, Shenton ME, McCarley RW. Selective deficits in visual perception and recognition in schizophrenia. Am J Psychiatry 1996;153:687-92. 
O'Donnell BF, Potts GF, Nestor PG, Stylianopoulos KC, Shenton ME, McCarley RW. Spatial frequency discrimination in schizophrenia. J Abnorm Psychol 2002;111: $620-5$

Pieretti M, Zhang FP, Fu YH, Warren ST, Oostra BA, Caskey CT, et al. Absence of expression of the FMR-1 gene in fragile X syndrome. Cell 1991;66:817-22.

Polat U, Sagi D. Lateral interactions between spatial channels: suppression and facilitation revealed by lateral masking experiments. Vision Res 1993;33:993-9.

Randolph C, Tierney MC, Mohr E, Chase TN. The Repeatable Battery for the Assessment of Neuropsychological Status (RBANS): preliminary clinical validity. J Clin Exp Neuropsychol 1998;20:310-9.

Roder V, Medalia A. Neurocognition and social cognition in schizophrenia patients: basic concepts and treatment. Basel: Karger; 2010.

Rousseau F, Labelle Y, Bussières J, Lindsay C. The fragile X mental retardation syndrome 20 years after the FMR1 gene discovery: an expanding universe of knowledge. Clin Biochem Rev 2011;32:135-62.

Sawatari A, Callaway EM. Convergence of magno- and parvocellular pathways in layer 4B of macaque primary visual cortex. Nature 1996;380:442-6.
Schechter I, Butler PD, Zemon VM, Revheim N, Saperstein AM, Jalbrzikowski M, et al. Impairments in generation of early-stage transient visual evoked potentials to magno- and parvocellular-selective stimuli in schizophrenia. Clin Neurophysiol 2005;116:2204-15.

Sharma T, Harvey P. Cognition in schizophrenia. Impairments, importance, and treatment strategies. Oxford: Oxford University Press; 2000.

Silverstein SM, Keane BP. Perceptual organization impairment in schizophrenia and associated brain mechanisms: review of research from 2005 to 2010. Schizophr Bull 2011;37:690-9.

Skottun BC, Skoyles JR. Contrast sensitivity and magnocellular functioning in schizophrenia. Vision Res 2007;47:2923-33.

Willemsen R, Smits A, Mohkamsing S, van Beerendonk H, de Haan A, de Vries B, et al. Rapid antibody test for diagnosing fragile $\mathrm{X}$ syndrome: a validation of the technique. Hum Genet 1997;99:308-11.

Woods SW. Chlorpromazine equivalent doses for the newer atypical antipsychotics. J Clin Psychiatry 2003;64:663-7.

Zangenehpour S, Cornish KM, Chaudhuri A. Whole-brain expression analysis of FMRP in adult monkey and its relationship to cognitive deficits in fragile $\mathrm{X}$ syndrome. Brain Res 2009;1264:76-84. 